\title{
GÉNERO Y SALUD PÚBLICA
}

\section{Gender and Public Health}

Entender la salud desde una perspectiva de género parece hoy más apremiante que en el pasado. En efecto, si hoy hablamos de género inmediatamente aparecen en la mente de cada uno de nosotras/os diferentes significados y asociaciones. En términos simples, aunque no simplistas, podríamos decir que cuando hablamos de género hablamos de una de las formas que determina nuestro estar en la sociedad, es decir, determina nuestra posición social. En el lenguaje de los determinantes sociales de la salud, el género es un eje o un determinante de estratificación social. De este modo, así como somos seres "sexuados" (sexo) también somos seres "engenderados" (si es que se permite usar este neologismo, como una traducción de "gendered"). Más aun, somos seres "sexuados"y "engenderados" simultáneamente.

Esto no resulta trivial, especialmente cuando hablamos de la salud poblacional, de la salud colectiva. En un principio, la perspectiva de género fue incorporándose en el análisis de los datos de salud pública reemplazando, casi como en una sinonimia, a la variable "sexo". Aunque eso aún se hace en algunos estudios (así como se habla de "clase social", cuando solo nos aproximamos a la medición del "nivel educacional"), se podría decir que cada vez existe mayor conocimiento y, por tanto conciencia, de la diferencia entre sexo y género. También hemos avanzado en entender que cuando hablamos de esta última, nos referimos a una categoría sociocultural y a un eje estructurante del poder y de la distribución de los privilegios en una sociedad. Género es una categoría que no se limita a reemplazar la variable sexo y que no hace referencia a la construcción sociocultural solo de lo femenino y del ser mujer (aunque gran parte de su estudio y las fuerzas sociales y políticas que han impulsado cambios de género, han sido protagonizados por mujeres).

El género se experiencia y se define de modo particular de acuerdo a la pertenencia, entre otros, a clase, etnia, edad u orientación sexual. La complejidad que nos abre esta perspectiva se configura en su interacción con estos otros ejes de estratificación social y de poder. Estos ejes o dimensiones de estratificación se intersectan, configurando desde la complejidad de esa convergencia, la posición e identidad de los sujetos sociales. En el lenguaje de la Teoría Feminista de la Interseccionalidad, las vidas humanas no pueden ser reducidas a categorías simples ni fijas. Para su análisis, se requiere el abordaje de las interacciones simultáneas entre diferentes aspectos de la identidad social, así como del impacto de los sistemas y procesos de opresión y dominación. La injusticia y la desigualdad social en salud se entienden desde esta base multidimensional.

Hablando de los dos pilares que, puede afirmarse, constituyen la salud 
pública, a saber el estudio de la salud de las poblaciones y la respuesta socialmente organizada a las necesidades de salud de estas poblaciones, podemos afirmar que el género se constituye en una categoría fundamental. El género, como construcción sociocultural y estructurante de poder, influencia el comportamiento, actitudes, relaciones y la forma en que a través del curso de la vida las personas y comunidades van viviendo, determinando las circunstancias, contextos, decisiones y oportunidades que afectan la salud de los distintos grupos sociales.

La incorporación de un enfoque de género en salud pública nos lleva, por una parte, a relevar las necesidades de salud de diversos grupos de personas en todas las fases del desarrollo de políticas y programas, rompiendo la tradicional -pero errónea- igualdad entre género y salud de las mujeres (al respecto, por ejemplo, ver en este mismo número el artículo de Núñez y Donoso). Incorporar el enfoque de género también nos permite analizar la propia respuesta socialmente organizada a estas diversas necesidades de salud, de-construyendo al sistema de salud como una institución "engenderada", es decir, como una respuesta socioculturalmente configurada, que como tal afecta el acceso y tipo de atención brindada a personas de distintas orientaciones sexuales, así como las relaciones y distribuciones de poder en el propio sistema de salud (sobre este punto se sugiere leer Martínez y Díaz "Evaluación sensible al género para la gestión de Servicios y Sistemas de Salud", en RChSP Vol. $21 \mathrm{No}, 2$, 2017).

La incorporación de una mirada de género a la salud pública implica abrir nuevas interrogantes, a partir del surgimiento de nuevos temas de interés y del volver a mirar, desde otra perspectiva, aquellos temas más tradicionalmente estudiados en salud pública. Aún más, implica observar el quehacer de nuestro propio campo de conocimiento y acción. Observar el quehacer de la salud pública y los cambios acaecidos en los últimos años desde un enfoque de género, permite, por ejemplo, analizar las formas en que se ha generado el conocimiento y quienes lo han producido, quienes han ocupado las posiciones de poder en el ámbito académico y del quehacer en salud pública, y qué repercusiones ha tenido aquello en el conocimiento y la acción del campo. La incorporación de una mirada de género permitiría el cuestionamiento y análisis del proceso de feminización de la salud pública, así como las implicancias, alcances y consecuencias de ese proceso.

Hablar de salud pública y género nos abre un abanico de temas, áreas de exploración y nos ofrece una perspectiva renovada y crítica para aproximarnos al registro, estudio y análisis de temas nuevos y otros ya largamente estudiados. El enfoque de género nos permite develar, comprender y actuar sobre las múltiples inequidades y las desigualdades estructurales que se imbrican para determinar la salud de los distintos grupos sociales. Nos ofrece una forma de observar y analizar el propio quehacer de la salud pública y sus principales instituciones. La incorporación de una perspectiva de género para la salud pública hoy en día es, en definitiva, fundamental e ineludible. 